\title{
Effects of Modern Dating Applications on Healthy Offline Intimate Relationships during the COVID-19 Pandemic: A Review of the Tinder Dating Application
}

\author{
Okoye Blossom Chisom \\ University of Port Harcourt, Port Harcourt, Nigeria \\ Email: blossomokoye624@gmail.com
}

How to cite this paper: Chisom, O. B. (2021). Effects of Modern Dating Applications on Healthy Offline Intimate Relationships during the COVID-19 Pandemic: A Review of the Tinder Dating Application. Advances in Journalism and Communication, 9, 12-38.

https://doi.org/10.4236/ajc.2021.91002

Received: November 25, 2020

Accepted: March 12, 2021

Published: March 15, 2021

Copyright ( 2021 by author(s) and Scientific Research Publishing Inc. This work is licensed under the Creative Commons Attribution International License (CC BY 4.0).

http://creativecommons.org/licenses/by/4.0/

(c) (i) Open Access

\begin{abstract}
This work is a review study on the outcome of online dating applications on offline mode healthful affairs during the corona virus outbreak. This study establishes the positive and negative effects social media dating applications such as the tinder app which is used as a case study for this work, have on healthy offline intimate relationships. The analysis further reveals future directives on how to stay clear of and also resist temptations that emanate from the use of social media dating app to maintain a healthy affair with the offline partner, especially during a pandemic. The study concludes therefore that due to the COVID-19 epidemic which resulted in loneliness and boredom due to adhering to the stay at home policy, there was a rapid increase of online dating applications especially on Tinder and had in so many ways, positively and negatively affected healthful offline affairs.
\end{abstract}

\section{Keywords}

Online Dating, Dating Applications, Healthy Relationships, Pandemic, Intimate

\section{Introduction}

The Corona virus (COVID-19) pandemic erupted in Wuhan, Hubei province, China. Residents who lived in Wuhan had some link to large seafood and live animals, markets which suggested that the mode of transmission of corona virus was from Animal to person. The Virus has been named "SARS-COV-2" and the disease it caused has been named "Corona virus disease 2019" (abbreviated "COVID-19"). The patients of corona virus started experiencing symptoms in Wuhan China in Dec 2019. Since then, there have been over a million reported 
cases around the world. The virus can be transmitted both by air and via direct and indirect contact. However, the most frequent way it spreads is via droplets. Like the other family belonging to the same family of corona viruses, it can cause mild flu-like symptoms such as cold, sore throat, cough, and fever to more severe ones such as pneumonia and breathing difficulties, and it can lead to death as well. Since no effective specific drug therapy has been found yet, nor any vaccine capable of limiting the spread of the virus, it is important for ways of preventing the spread of this infection to be established, some of these prevention measures include: reducing direct contact, avoiding direct unprotected contacts with secretions (especially coughing, touching used paper tissues with bare hands, avoiding direct contact within $2 \mathrm{~m}$ and $>15$ minutes, reducing contact with people in a closed environment (especially, classrooms, meeting rooms, hospital, waiting rooms, etc.) beyond 15 minutes and at a distance of less than 2 $\mathrm{m}$, frequently washing of hands, wearing of Clean Gloves, wearing of disposable masks, most importantly, staying at home.

Most businesses, companies, and agencies were locked down, and at the time most countries placed their citizens on a compulsory stay at home curfew, this was to help contain the spread of the virus through social distancing. This came as a revolution for many modern online dating Applications; as a good number of them went on to add video features to their Applications. Tinder, a popular online dating Application was not left behind as they also stepped up their game in the same light. However, this didn't go down well for some healthy offline intimate relationships, as these Online Dating Applications may or may not have posed as a distraction and threat. This article aims to establish how the COVID-19 pandemic and lockdown had negatively and positively affected offline healthy affairs which are known to be built on trust, communication, and honesty, using the Tinder App as a review case study. This is done in the view of the following objectives to:

1) examine the concept of online dating and its current situation, which would be statistically proven.

2) explore the effects of the COVID-19 pandemic on both online and offline relationships.

3) identify the characteristics of a healthy relationship.

4) analyze the advancements of the tinder dating application during the COVID19 pandemic.

5) determine the positive and negative effects of tinder on healthy offline intimate relationships during the corona virus outbreak.

6) establish future directives on how to maintain a healthy offline relationships while using online applications, using a pandemic.

\section{Literature Review}

\subsection{Online Dating}

According to Wikipedia, Dating is a stage of romantic relationships in humans 
whereby two people meet socially with the aim of each accessing the others' suitability as a prospective partner in an intimate relationship. For as long as humans have recognized the urge to form romantic relationships, they have also recognized that finding an appropriate partner can be challenging, and that sometimes it is useful to get some help. From the Jewish shadchan immortalized in the musical Fiddler on the Roof, to the khastegari customs of Iran, to the arranged marriages still prevalent in parts of Southeast Asia, there is a tradition-millennia old-of romantic relationships arising not only from chance encounters between two individuals but also from the deliberate intervention of third parties (Coontz, 2005). For most of those millennia, the resources available to these third parties remained the same: a broad social network, strong opinions about the sorts of people who belong together, and the willingness to apply those judgments to the formation of actual couples (Ahuvia \& Adelman, 1992). In the modern age, the desire to find a romantic partner endures, as does the sense that doing so can be challenging. But the resources available for meeting these challenges have changed, and many of these changes can be traced to the invention, spread, and now ubiquity of the Internet. According to recent data, some $30 \%$ of the 7 billion people on our planet now have access to the Internet (InternetWorldStats.com, 2011). In North America, where Internet usage is highest, that figure reaches $78 \%$. Every domain of contemporary life, from commerce and politics to culture, is now touched by the Internet in some way. With respect to forming romantic relationships, the potential to reach out to nearly 2 billion other people offers several opportunities to the relationship-seeker that are unprecedented inhuman history. First, whereas the "field of eligibles" (Kerckhoff, 1964) for an individual was once limited primarily to members of that individual's social network, the Internet now affords access to a vastly wider network of potential partners who would have been unknown or inaccessible in former eras. Second, whereas interaction between potential partners once depended on their proximity to each other, the Internet now facilitates nearly instantaneous communication via multiple channels (i.e., text, voice, image, and video) without partners having to be in the same location and even without partners' conscious awareness (e.g., by allowing others to view one's information online). Third, whereas the choice of a mate once relied largely upon the individual's intuitions and personal opinions, the Internet promises to create matches between suitable partners using new tools that draw upon data provided by thousands, or millions, of users. Recognizing the unique possibilities afforded by the Internet, numerous commercial Web sites have arisen to provide these services to users seeking romantic relationships. Specifically, the past 15 to 20 years have witnessed the development of Web-based companies that specialize in providing some combination of:

1) access to potential romantic partners.

2) communication with potential romantic partners.

3) matching with compatible romantic partners. 
Each year, millions of hopeful relationship seekers use these sites, often paying substantial fees for the privilege. To attract customers, online dating sites typically emphasize two aspects of the services they offer. First, they emphasize that their services are unique to dating through the Internet; that is, the sites are offering a service that cannot be duplicated in any other way. The homepage of PlentyOfFish, for example, claims that membership on the site gets you access to "145 million monthly visitors" and that "you are not going to find any other site that has more singles looking to meet new people" (PlentyOfFish.com, 2011). Presumably that claim refers not only to other Web sites but also to other venues where single people gather to meet, such as bars, parties, churches, or libraries. Second, online dating sites emphasize that forming relationships using their services is superior to dating offline. The Web site for eHarmony, for example, asserts that the services the site offers "deliver more than just dates"; instead, it promises connections to "singles that have been prescreened on. scientific predictors of relationship success" (eHarmony.com, 2011). The implication is that eHarmony possesses knowledge about relationships that most people lack and that applying this knowledge will lead to more favorable relationships than subscribers would experience without this knowledge. The OkCupid Website also implies access to knowledge unavailable to the layperson with the straightforward claim, "We use math to get you dates" (OkCupid.com, 2011). By referring to millions of users, science, and math, online dating sites suggest that meeting romantic partners online is not only different from, but also better than, searching for partners in conventional ways. Each of these claims raises questions that can be answered empirically. For example, with respect to uniqueness, does the rise of online dating represent a fundamental change in the process of forming and maintaining romantic relationships? With respect to superiority, are the users of online dating sites in fact improving their chances of experiencing positive romantic outcomes compared to individuals who rely entirely on more conventional methods of meeting partners? Addressing such questions is of great public importance for several reasons. First, romantic relationships-their presence, as well as success or failure-play a central role in individuals' physical and emotional well-being. The need to connect deeply with others has been described as a "fundamental human motivation" (Baumeister \& Leary, 1995). When that need is fulfilled by a satisfying intimate relationship, couples experience better health (Cohen et al., 1998), recover from illnesses more quickly (Kiecolt-Glaser et al., 2005), and live longer (Gallo, Troxel, Matthews, \& Kuller, 2003; HoltLunstad, Smith, \& Layton, 2010). Indeed, the presence of a satisfying intimate relationship is one of the strongest predictors of happiness and emotional wellbeing that has been measured (Diener \& Seligman, 2002). Loneliness and distressed relationships, in contrast, predict increased risks of depression and illness (Cacioppo et al., 2002) and incur enormous national costs in terms of lost productivity (Forthofer, Markman, Cox, Stanley, \& Kessler, 1996), and they are the leading reasons why people seek therapy or help from lay counselors in the 
United States (Veroff, Kulka, \& Douvan, 1981). Thus, online dating sites are treading in deep waters, and whatever the implications of these sites, those implications are likely to have strong ripple effects. Second, as commercial dating sites become increasingly accepted as a means of forming romantic relationships, more and more couples are meeting online (Rosenfeld, 2010). One industry trade report estimated that almost 25 million unique users around the world accessed an online dating site in April, 2011 alone (Subscription Site Insider, 2011). If some of the individuals who form relationships online would not otherwise have found partners, then the availability of the unique services that the Internet provides may be a boon to relationship seekers. Moreover, if relationships formed through the Internet are in fact superior to those formed via more conventional means, then the increasing popularity of online dating sites has the potential to boost happiness and to reduce the great suffering and costs associated with relationship distress and dissolution (e.g., Amato \& DeBoer, 2001; Forthofer et al., 1996; Kiecolt-Glaser et al., 2005; Sbarra, Law, \& Portley, 2011). If the claims of online dating sites are unfounded, however, then increasing numbers of people are pursuing relationships that are actually no better than matches formed offline and that may even be worse. A third reason to evaluate the claims of online dating sites is that online dating now consumes vast resources in the United States and around the world. Online dating has grown into a billiondollar industry, and it is one of the few growth industries during a period of worldwide recession. In pursuit of these revenues, online dating sites spend hundreds of millions of dollars annually to promote the value of the services they provide (Nielsenwire.com, 2009). Believing these messages, millions of users are not only spending their money on memberships and subscriptions, but they are also investing considerable time. One estimate suggests that users spend an average of 22 minutes each time they visit an online dating site (Mitchell, 2009), and another suggests that they spend 12 hours per week engaged in computerbased online dating activity (Frost, Chance, Norton, \& Ariely, 2008). Across millions of users, this represents an enormous allocation of time that might otherwise be spent on other activities, including engaging in social interactions offline. These costs in time and money are warranted if online dating actually provides improved, cost-effective access to successful romantic relationships. If such evidence is lacking, however, then people seeking romantic partners may be wasting significant time and money that they could direct toward more productive activities. Online dating has become a common practice for people looking to form new relationships (Whitty \& Carr, 2006). Of the 54 million single people in the U.S., 40 million have tried online dating (StatisticBrain.com, 2012). Today, one in ten Americans use online dating sites (Smith \& Duggan, 2013). Over the years, online dating has seen a steady increase. According to a 2013 Pew survey, $11 \%$ of adults have used online dating sites or mobile dating apps up from just 3\% in 2008 (Smith \& Duggan, 2013). Sixty six percent of online daters have gone on a date with someone they met through a dating site or mobile application 
compared with 43\% in 2005 (Smith \& Duggan, 2013). Additionally, 23\% of online daters said they have met a spouse or long-term relationship through similar sites compared with $17 \%$ in 2005 (Smith \& Duggan, 2013). A 2009 nationally representative survey of 4002 adults investigated how people met their current partners. Among the participants who met their partners between 2007 and $2009,22 \%$ of heterosexual couples met on the Internet, which made the Internet the second most common way to meet a partner, only behind meeting through friends (Rosenfeld \& Thomas, 2010). This is consistent with a similar finding from Pew, which determined that $88 \%$ of Americans still meet their significant other offline (Smith \& Duggan, 2013).

\subsection{Theoretical Framework}

\subsubsection{Uses and Gratification Theory}

This research incorporates the uses and gratifications (U\&G) theory to identify how and why consumers use mobile dating technology. Defined by Blumler, Katz, and Gurevitch (1974), U\&G research investigates user motivations and what people do with 17 mass media. Since the definition of mass media has come to include elements of emerging technology, $\mathrm{U} \& \mathrm{G}$ is an appropriate framework for explaining how and why audiences select to download and use Tinder. Compared with studies on passive media effects, $U \& G$ is an audience-centered approach, which posits that media users are active in their selection and have specific needs that drive media adoption (Rubin, 2009). Other objectives of U\&G are to understand motives for media behavior and to identify functions or consequences of certain needs (Katz et al., 1974). Needs are the "combined product of psychological dispositions, sociological factors, and environmental conditions," (Katz, Haas \& Gurevitch, 1973). Katz, Hass and Gurevitch (1973) developed 35 needs taken from the mass media and divided them into five categories: cognitive needs, emotional needs, personal integrative needs, social integrative needs, and tension release needs. Similarly, McQuail (1983) summarized four core reasons for media use: information, personal identity, integration and social interaction, and entertainment. Past studies on U\&G determined that media gratifications are largely based on a user's pre-existing needs, rather than specific technological features of media (Greenberg, 1974). Needs drive the use or gratification acquired from different media contexts, but as media becomes more interactive, it's important to remember differences between traditional media (e.g., radio, television, newspapers) and newer forms of media (e.g., video games, tablets, smartphones), which usually offer Internet connectivity and more options for user gratifications. Staying akin with the U\&G approach, media will compete with other information sources for user gratifications (Katz et al., 1974).

\subsubsection{Attachment Theory}

The theoretical background for this study is based partially on attachment theory. According to Seigel, attachment "is an inborn system in the brain that evolves in ways that influence and organize motivational, emotional, and memory processes 
with respect to significant caregiving figures" (Seigel, 1999). In other words, attachment is a connection forged between infants and their primary caregivers in the early stages of life. Whether infants are securely or insecurely attached affects the manner in which they experience future relationships, and the world around them (Seigel, 1999). Attachment theory has also been applied to adolescent and young adult development (Allen, 2008). According to Allen (2008), adolescence is a time where young adults begin to separate and individuate from peers. As a result, young adults form attachments to their peers, and eventually their romantic partners (Allen, 2008). Therefore, examining this topic through an attachment-based lens may shed light on how and why young adults form attachments to partners via online dating and what, if any, problems they might experience in forming attachments this way.

\subsubsection{Consumer Culture Theory}

Another way to understand the online dating phenomenon is through consumer culture theory. According to Arnould and Thompson (2005), consumer culturetheory consists of "a family of theoretical perspectives that address the dynamic relationships between consumer actions, the marketplace, and cultural meanings," (p. 868). In essence, consumer culture theory, or CCT for short, examines how the products that people buy and the larger culture they participate in shapes their identities and self-concepts (Arnold \& Thompson, 2005). This feedback loop is cyclical, and the culture at large is, in turn, also shaped by the consumption patterns of individuals (Arnold \& Thompson, 2005). Looking through a CCT informed lens, the online dating phenomenon can be explained by viewing online dating services as market products and users as consumers. In fact, as one research study discovered, as online environments continue to gain popularity, more and more individuals are identifying themselves based on how and what they present online (Schau \& Gilly, 2003). These findings suggest that online users can form a sense of self based on a media product (Schau \& Gilly, 2003). Under this assumption, it is possible that online dating has achieved such a high level of popularity because it is a product of our larger consumption based society. Examining online dating from a consumer culture perspective could illuminate how our culture is formed and changed by the products and services (like online dating) that we purchase and use. Social Constructionism The concept of racial and gender discrimination online is based on social constructionist theory. Social constructionism is defined as the belief that a subjective reality does not exist (Galbin, 2014). Rather, social construction postulates that all realities are created, or "constructed" through the social exchanges of human beings. This means that all "realities" are subject to change based on the context of the interpersonal interactions going on at any given time. This also means that no two persons' perception of reality will never be entirely the same. When applied to gender and race, social constructionism indicates that the values we assign to each race and gender are functions of the time and dominant cultural milieu around us, and they do not reflect an actual reality (Galbin, 2014). Societal phe- 
nomenon, like the internet and online dating, shape how classifications like gender and race are conceptualized. For example, a study conducted by RightlerMcDaniels and Hendrickson examined how current ideas or gender and race are shaped through the internet using language (2014). Researchers demonstrated how social media sites like Twitter allowed for the widespread use of slang like "hoes" (Rightler McDaniels \& Hendrickson, 2014). This charged language had the capability to create new discourses surrounding gender and race and illustrates how social media affects dominant and youth culture

\section{A Compiled List of Few Frequently Used Modern Dating Applications across the World}

Modern dating apps can be simply referred to as online applications that were created for the sole purpose of finding a romantic partner in this modern age. They connect people all across the world through a means of text-chat messaging, voice calls and video calling features. Information on these compiled applications listed below can be found on a Google search if one has a phone and a working internet connection. These applications include:

1) Tinder: One of the best-known dating apps around. Tinder allows users to "swipe right" on images of users if they are interested in them and "swipe left" if they are not. It uses minimal interface and bases its matches on location on the user. As the king of dating apps, Tinder is the most talked about dating app in history. With over 9 billion matches since it first launched in 2012, Tinder's has had it's fair share of success stories and nightmares.

2) Bumble: Anotherdating app designed with women in mind. Bumble is one of the more of the more popular dating apps among women due to its feature that only allow women to send a messge to first.

3) Hinge: Hinge hinges on the fact that you have a face book account. Simply put, this dating app finds matches for you that already exist in your wider social network. So, anyone can you get to chat with wont be a stranger in the strictest sense.

4) OKCupid: OkCupid is well known for its personality test and savvy data understanding when it comes to dating. On its online dating app, it allows users the freedom to express themselves; it is very LGBTQI+ friendly with 13 different sexual orientations and 22 gender identities.

5) Coffee meets Bagel: it is aimed at busy professionals who will get sent one match (a "Bagel") by the app per day at noon-just in time for lunch-which you can either like or pass on.

6) XO: Xo uses games to break the ice. Quizzes, drawing games and othee party activities let you share a laugh with somebody new and maybe forge a connection that leads to relationship. You find matches by filling out a profile and meeting with someone who has similar likes.

7) Tastebuds: Meeting people through music is the name of the game for Tate buds. With Tastebuds, you can find people who have the same taste in music as 
you (people to join you at random concerts that your friends won't come with you to), and you can even send them a song to break the ice.

8) Raya: Raya is an IOS app which originally began as a low-key dating service, but also began to be used to make professional networking contacts and friends, particularly among those in the creative industries. You don't get in either; prospective members will need to send in an application, which will be vetted, before you are admitted to Raya or not. If you are let into the club, then membership will cost $\$ 7.99$ per month, or $\$ 29.99$ over 6 months.

9) Match: This is probably one of the most-well known dating apps. Promising users a chance at real, long-term success, its app is not too different from its desktop site. Upload your profile, get matches and meet people-simple.

10) Happn: Happn gives you the chance to meet people you've literally crossed paths with during the day. The fact that these people were actually near you at some point makes them a little more real and a little less internet. Every time you cross paths with another Happn user, their profile will come up on your timeline allowing you to like (or ignore) them, and if they like you too, you can start nattering.

11) Plenty of Fish: POF is owned by the match group and is an internet-dater favourite because you can view matches (and sort through them, i.e. who was last online, newest user, etc.) and communicate with them for free. They use an advanced matching algorithm to find the best suitor for you. The site has over 3 million active daily users and $85 \%$ of all its traffic comes from the mobile app.

12) The league: The League is a self-proclaimed "Elite" dating app for successful singles. It hides your profile from friends, business contacts and coworkers, and only gives you up to 5 potential matches per day who you can say yes or no to. Matches have a three-week expiration date. True to elite form, there's even a waiting list to get on it.

13) Her: Her is a much needed breath of fresh air on the dating app scene, so it is dedicated to helping queer, bisexual and lesbian women find their ideal partner. The app is free and you can view profiles, add friend and start chats at no extra cost.

14) Clover: Clover is a fast free dating app which prides itself in taking the simplicity of Tinder and combining it with the science of match.com. You can filter matches by relationship intention: looking for friends, hookup, casual dating or something serious, and search people by body type, height, ethnicity, and even occupation.

15) Lumen: All accounts in Lumen re verified, and profiles are detailed-with at least three photos and a lengthy bio. There are no paywalls on the site that but you can only start six conversations per day as a free member. You can upgrade to 12 conversations per day if you subscribe for 24.99 Euros per month.

16) Meetme: This is more of a chat-based service. You can see people based on location who are available and ready to chat and then get to know them. It's free for the basic features like chatting and updating your timeline (think Twitter) to 
let people know what you're up to.

17) Skout: Skout says it's the world's largest app for meeting new people all over the world, no matter where you are. Shake your phone to chat to random people and use the passport section to "virtually travel" anywhere in the world. They have 2 separate communities, one for teens and one for adults and claim to have zero tolerance for bad behavior.

18) Badoo: There are over 298 million people on Badoo (and counting-they have a cool counter on their site showing the growing number of Badoo users which rises by the second). They have a Tinder-like game called "Encounters" (or Hot or Not) where you can match with other users and it's available on desktop and mobile.

19) Aisle: Aisle is the dating app for those looking for meaningful relationships. It's not likely that someone who is in search of just a hook-up will be on this dating app, so if you want to get married or have a long-term relationship, this is your direction.

20) Eharmony: eHarmony is another serious dating site that prefers to connect its users based on personality. With its focus on marriage, it's a solid choice for those in their 20's or early 30's who wnt to upgrade to a paid dating app.

21) Zoosk: Rather than using a matchmaking personality test, Zoosk pulls data from all social accounts, allowing for a more efficient sign-up process. Zoosk also has a large number of members, giving new users even more opportunity to match with lots of different types of people.

22) Elite Singles: EliteSingles is one of the best apps for people looking for serious, long-lasting relationships with professional singles. While appearances matter, most people know that you need more to create a relationship. The membership of the EliteSingles app is from 30 - 50, so with the benefit of age comes wisdom to know that you shouldn't judge a book by its cover. The app also does not need any of your social network information to get you started. All you need is an email address and a password sign up.

\section{A Healthy Relationship and Its Characteristics}

Communication is a key part of building a healthy relationship. A healthy relationship encompasses these five important traits: Communication, Trust, understanding, honesty, and respect. Some of Its characteristics include:

1) Speak openly to one about thoughts and feelings;

2) Listen to each other and compromise;

3) Do not criticize each other;

4) Feel heard when expressing feelings;

5) Feel supported to do things they like;

6) Celebrate each other's accomplishments and success;

7) Do not pressure the other to do things they don't want to do;

8) Do not constantly hinder each other to spend time with friends and fami- 
lies;

9) Create an environment of playfulness and fondness;

10) Always stay committed to your partner.

\section{The Effects of the COVID-19 Pandemic on Both Online and Offline Healthy Relationships}

The COVID-19 pandemic has transformed our relationships in extraordinary ways, forcing us to live closer together with some people and further apart from others. Life in lockdown has kept some couples who had established healthy offline relationships apart in a factual sense, and such necessitating close and constant contact with friends made online. This is because most persons get busy with their phones to ease off boredom and loneliness that comes with the covid0-19 rule, social distancing. A lot of offline lovers who were set apart during the quarantine period might suffer from; miscommunication, lack of trust, and honesty.

These digital natives, through online applications, have enjoyed the freedom to manage their social lives and romantic entanglements that the previous generations lacked. Home alone and in some cases without a job, single people are sending more time swiping right on dating applications to find love particularly in the cities hit by the virus. A great deal of these dating applications has reportedly increased tremendously in messages sent during the period of the pandemic.

\section{Background Information on the Tinder Dating Application and Its Advancement during the COVID-19 Pandemic}

According to Wikipedia, tinder is a social networking and online dating application which was firthat allows users to anonymously swipe to like or dislike other profiles based on their photos, a small bio, and common interests. Once two users have matched, they exchange messages. In September 2012, Sean Rad and Justin Mateen piloted a mobile matchmaking application at the University of Southern California.

Within a week, the aptly named "Tinder" had gone from 300 to 1000 users. Today, Tinder is offered in 24 languages and has generated 1 billion matches, with 800 million swipes per day. It has since been considered the fastest-growing dating application in the United States (Baxter \& Cashmore, 2013). As stated by Rad, "We want to be the company you turn to when you want to meet somebody" (Colao, 2013).

According to a BBC report on 20th may 2020, tinder users made 3 million swipes worldwide on the $29^{\text {th }}$ of March 2020 (when most countries began their lockdown and social distancing rules), the most the app has ever made in a single day. In the United Kingdom, daily conversations rose by $12 \%$ between midFebruary and the end of March. These statistics explains in the simplest terms 
that during the lockdowns, people depended mostly on their social dating apps, especially the tinder dating application, to meet new friends and keep themselves busy.

Also, according to a report from Verge on June 9, 2020, tinder and its parent company "match" group have weathered the COVID-19 pandemic relatively well, all things considered, the use re-engagement is up as it interest around new product features like video calls. More than six years after its launch, tinder is finally introducing a one-on-one video calling feature that it says will be heavily moderated for content and safety. Also, a live mint report stated that tinder had rolled out the "passport" feature, initially a paid feature for tinder plus and gold subscribers that were later made available for free members can now search by city, or drop a pin on the map to begin liking, matching and chatting with tinder members in a destination of their choice and not have to navigate around their current location, as was the case earlier.

\section{Effects of Tinder on Healthy Offline Intimate Relationships during the COVID-19 Pandemic}

As earlier explained in previous texts, a lot of countries went on both total and partial lockdown to regulate the crowd and adhere to social distancing as this is the only way to contain the spread of the coronavirus. This resulted to a lot of persons staying at home which led to boredom (especially those without a job), the boredom brought about the massive download of some social media dating applications as well which is in no doubt, one of the best ways to make friends and kill off the boredom. Now we have gotten a broad understanding on why a lot of individuals downloaded dating applications during the COVID-19 outbreak, we would in a tubular form, draft out some of the possible effects (both the positive and negative effects) these online dating could have on their users, especially ones who already had an established and healthy offline intimate relationship.

\subsection{Positive Effects}

Table 1 shows 6 positive effects of tinder on healthy offline intimate relationships during the COVID-19 pandemic which are explained below:

1) Understanding the value of face to face communication and attention: Before the pandemic, everyone had the freedom to walk around and visit their partners at will especially in times of relationship crises, and they get to resolve it through face to face communication and possibly get the right attention they desire. We would all agree that online dating applications cannot give us that satisfaction and desire. No matter how many persons you have liked, matched and chatted with on the tinder dating application, the only thing that connects him or her with the online lover is just a phone and a working internet that is not enough to create a strong communication unlike face to face communication which involves eye contacts which should always be valued. 
Table 1. Positive and negative effects of tinder on healthy offline intimate relationships during the COVID-19 pandemic.

\begin{tabular}{ll}
\hline \multicolumn{1}{c}{ Positive } & \multicolumn{1}{c}{ Negative } \\
\hline $\begin{array}{ll}\text { 1) Makes one understand the value of face to face } \\
\text { communication and attention }\end{array}$ & 1) Low communication \\
$\begin{array}{ll}\text { 2) Helps one discover the difference between real } \\
\text { and fake identities }\end{array}$ & 2) Lack of commitment \\
$\begin{array}{ll}\text { 3) Aids one to detect and recognize that dating } \\
\text { applications cannot fully satisfy one's sexual urge }\end{array}$ & 3) Leads to unnecessary comparisons \\
$\begin{array}{ll}\text { 4) Discovering love } & \text { 5) Little or No Attention } \\
\text { 5) Fear of rejection } & \text { 6) Trust issues } \\
\text { 6) Ease of communication } & \text { 7) Deception and Lies } \\
\text { 7) Self Worth Validation } & \text { 8) Sexual Risk } \\
& \text { 9) Self exposure to meeting dangerous } \\
\end{array}$
\end{tabular}

2) Discovering the difference between real and fake identities: it is no news that there are a lot of fake identities in the tinder app where people get to create accounts with fake pictures and personalities. In an offline personal relationship, especially healthy ones, one can easily discover the realness in their partners and also fakeness (unhealthy relationships) by getting to notice how the partner looks, behaves, reasons, and relate with you physically. However, this is not so in the tinder dating program as one can hardly tell since all that gets to connect both lovers is a cell phone, the app, and working internet.

3) Detecting and Recognizing that dating application software's cannot fully satisfy one's sexual urge: I believe this is the best of the positive effect already listed, not taking it personally but a lot of persons believe that sex is important in a healthy relationship. If this is true, how then can one rightfully and fully satisfy his or her sexual urge through a phone? I used the word "rightfully" and "fully" because one can decide to use masturbation as an escape root but we will agree that it is never the right way to go about it and might eventually not give one the satisfaction he or she desires. However, one can still meet up with their tinder date after the pandemic, and satisfy their sexual urge "fully".

4) Discovering love: one of the main reasons people go for online dating application is because they intend to find and discover love, relationships and have that thrill of excitement while talker to their online lover. During the pandemic, a lot of persons downloaded the tinder app, some to kill boredom, others to find love. Some of the persons who are the quest for love, might have an offline relationship, but most likely an unhealthy one. This doesn't mean one can only find healthy relationships on social dating apps, but when they tend to spend a lot of time with a person in the app, chatting quite intimately, one is likely to fall in love even without meeting yet.

5) Fear of Rejection: while signing up for the tinder app, one gets to upload a 
lot of pictures on their profile, so they get to select the best filtered photos. On thi note, anyone who gets to view their profile gets to be wowed amd there would be no room for rejection unlike face to face meeting where the real you is seen. Although this can be deceiving, it can be agreed that most people go for the heart rather the face this could be seen if a good relationship has been formed and sustained online.

6) Ease of Communication: it only takes a mobile phone, a working mobile network and a signed in dating application to get to your online love. It is easy and comfortable, this is because a mobile phone is flexible in nature, so one gets to carry it around with them at their own pace, and still get to communicate uninterrupted with their online partner.

7) Self worth Validation: When a Tinder user discovers that they get new admires and matches by the minute, it gives them a high level of self esteem and worth. This is because it mkes them feel wanted, feel cute and feel loved especially if the person had just gotten off a depressing relationship.

\subsection{Negative Effects}

Table 1 presented 9 negative effects of tinder on healthy offline intimate relationships during the COVID-19 pandemic which are explained below:

1) Low communication: While trying to stay at home to help contain the corona virus, and one decides to download the tinder dating application, he or she is allowed to like as many persons as they so desire and might have a lot of matches too, for example, a 100 matches, 70 might decide to chat them and 50 might be giving all the right vibes that they desire to kill boredom, now when one's online lover is getting all these intense communications, what then happens to the offline lover? Recollect in our list of what a healthy relationship should consist of, we added communication as an essential part of it. When there is low communication in a relationship (especially in an offline relationship and since the COVID-19 havoc has put one on the loneliness pathway) it could lead to depreciation of love, and at worst put an end to the relationship.

2) Lack of commitment: Due to the COVID-19 experience a lot of people now rely so much on dating applications and also commit their time and resource on it as well, thereby committing less to their offline (healthy) intimate affair. To be able to establish and sustain a solid healthy relationship, one must fully commit essentially their time and resources to their offline partner to scale through the loneliness temptation that the corona virus pandemic brought upon the masses.

3) Leads to unnecessary comparisons: people tend to compare what they see and feel on these online dating apps (such as attention, communication, and physical attributes) to what they have on in reality. They would want their offline relationships to look like that which they have online. first and foremost, no one likes to be compared to another by the partner in whatever sense, so when a person starts comparing their online lovers to the offline one, then they are breaking another essential component of a healthy relationship which is "re- 
spect" and respect is simply defined as having due regard for someone's feelings, wishes or thought. So if one is indeed in a healthy (offline) intimate relationship, then he or she should not hurt his or herpartner's feelings by unnecessary comparing them with another especially one met through a dating site, which in another sense, might have a fake identity.

4) Little or No Attention: Recent reports had it that there was a massive increase in the number of swipes made by tinder users at the time of the corona virus havoc. This simply summarizes the fact that a lot of people relied on the app to get attention from a connected user especially when their offline lover might not be given them all the attention they require due to the social distancing rules. As explained in a previous text, a person gets to chat with as many personas he or she dims fit especially if matched in tinder, so obviously, there will be fewer cravings for attention. Nevertheless, if all the attention is given the offline lover(s), then he or she might feel a sense of denial and rejection as they are likely to receive little or no attention.

5) Trust issues: After I had discovered the right title for my article, I decided to download the tinder application to check it out myself, since it was my case study. While on the app, I noticed that "hookup s" was the order of the day. At first, I thought hookups meant meeting up with a person but that wasn't the case, as everyone who asked for a hookup with me on the program, meant sex. I also understood further that the app is being used as a sex meeting platform especially for those in the prostitution business to get their clients. Also, I found out that those who wrote "no hook-ups" in their bio were in for it but only wrote that just in case one who they know or knows them wouldn't see what they are up to (as this is possible since the tinder app requires that your location be switched on before one can access the software, this is to help search for friends around one's environment plus anyone (both matched and unmatched) can view your bio's). This could bring about trust issues because whereby a person finds out that his or her partner is in the tinder app, he or she might come up with the mindset that the partner is in it for the hookups and shouldn't be trusted.

6) Deception and Lies: have you heard of the random quote "what I ordered for Vs What I got". This is exactly what one would experience while trying to make friends from online dating apps. The looks, the body physique could be built on deception and lies especially with the help of good phone camera qualities and filters, people tend to look more attractive on the dating apps profiles than in person.

7) Sexual Risk: meeting a person online in person takes a lot of courage. First, endeavor to meet the person in $\mathrm{n}$ open area before going private. This is to ensure your safety as you would be able to relate and observe the date's personality while talking with them. It is not advisable to go private with an individual you had just met on social media, to avoid sexual risk such as; rape, molestation etc.

8) Self Exposure to Meeting Dangerous People: while using the tinder app, it 
is compulsory to have you location on, on your mobile phone before accessing the app, this is to ensure you get to meet individuals living around your state of residence. However, this is not a guarantee that your date would turn out to be a nice person, that is why it is advisable you both meet in an open environment before taking it private to avoid exposing yourself to meeting dangerous people such as; kidnappers, arm robbers, ritualists etc. who would have nothing but ulterior motives to harm you.

\section{Statistical and Theoretical Framework on the Negative and Positive Effects of Online Dating Applications Especially on Offline (Healthy) Relationships}

\subsection{Negative Effects}

This section reviews risks in relation to the use of online dating. A total of ten studies were identified. There were six qualitative studies (Best \& Delmege 2012; Couch \& Liamputtong 2007; Couch et al. 2012; Erjavec \& Fišer 2016; Heino et al. 2010; Vandeweerd et al. 2016) and one paper which contained two studies: one qualitative and one quantitative (Sánchez et al. 2015). Three of the studies were purely quantitative (Cali et al. 2013; Choi et al. 2018; Solis \& Wong 2019). Additionally, two studies utilised female-only samples (Cali et al. 2013; Vandeweerd et al. 2016). According to the studies found in relation to perceived risks, there appears to be agreement on the existence of potential dangers of online dating. Vandeweerd et al. (2016) in an interview-based study with 45 women aged 50 years and older (mean age $=57.3$ years) found International Journal of Mental Health and Addiction that there was acknowledgement of risks, such as pervasive lying, attempted financial exploitation, and unwanted electronic sexual aggression (Vandeweerd et al. 2016). Moreover, Solis and Wong (2019) in their study in mainland China with 433 users of dating apps (mean age $=30$ years; $57.5 \%$ males) reported five categories of perceived risks: lies and deception, sexual risk, dangerous people, self-exposure, and harassment (Solis and Wong 2019). There were some shared perceived risk categories identified by these two studies: lying, finding people with ulterior motives, and aggression. In another study, with a female-only sample from a Midwestern University in the USA (mean age $=24.36$ years), Cali et al. (2013) carried out a vignette study comparing two different dating scenarios (i.e. online vs. offline). Participants were randomly assigned to one of the two conditions and were given a description. Following this, they were asked to complete the Dating Self-Protection Against Rape Scale (Moore \& Waterman 1999) and some items on internet usage. After analysis, results showed a difference between the two groups. Online dating scenario participants placed more importance on self protective behaviours, and those who had never used online dating before scored the highest in self-protective behaviours. Here, it appears that time spent using online dating mitigates the perceptions of risks which could lead to the underestimation of potential dangers. Further research needs to verify this hypothesis. Choi et al. (2018) stu- 
died a sample of 666 students from four different universities in Hong Kong (mean age $=20.03$ years) and collected data on the use of dating apps and experience of sexual abuse with the subscale of the revised Conflict Tactics Scale (Straus et al. 1996). The data showed that users of dating apps were more likely to have been sexually abused than nonusers in the past year. The use of online dating apps was also associated with lifetime sexual abuse, especially among sexual minorities (i.e. bisexual/homosexual males). These data need to be interpreted cautiously because the data did not discern whether the abuser was met online or offline. Further studies should discriminate whether or not the abuser was met via dating apps. Among adolescent populations, Sánchez et al. (2015) carried out two studies. The first study was qualitative, with focus groups including 16 participants (eight males) with ages ranging from 14 to 17 years. The focus group data analysis resulted in identifying several factors which were later included in the development of a scale (second study). The scale, namely the Cyberdating Q_A, assesses the quality of online dating among adolescents over six dimensions (online intimacy, emotional communication strategies, cyberdating practices, online control, online jealousy, and online intrusive behaviour). Couch and Liamputtong (2007) interviewed 15 participants from Melbourne (Australia) via online chat, eleven males aged between 24 and 44 years. After carrying out thematic analysis of the transcripts, the main findings reported that participants' management of risks was dependent upon the control they had over their own personal information on the online dating site (e.g. whether they can change their name, not showing telephone number and/or address). In a later study, Couch et al. (2012) carried out a qualitative study with 29 participants from Australia, 12 females, aged between 18 and 70 years (mean age $=$ 32.83). After conducting the interviews via an online chat platform, they found that participants identified risks such as deceit, sexual risks, emotional and physical risks and risks of encountering dangerous and untrustworthy people. Additionally, one of the key features of online dating (i.e. the screening of multiple profiles in order to select potential partners to establish an interaction which could later lead to an offline date) appears to have counterproductive effects on the users, such as partners' objectification and reduced energies for dating. Heino et al. (2010) reported objectification International Journal of Mental Health and Addiction of the potential dates in a study with 34 American online daters $(50 \%$ females, mean age $=42)$ from a large dating site, all of them living in Los Angeles. Participants used many marketplace metaphors when referring to screening profiles, which were themed into five categories: 1) other market's worth, 2) own market's worth, 3) shopping for perfect parts, 4) maximising inventory, and 5) calibrating selectivity (Heino et al. 2010). Another study carried out with 38 older Slovenian adults between 63 and 77 years of age (18 females) found that participants used economic metaphors (e.g. the best of what the market offers, to be back in the market) when speaking about their experience of online dating (Erjavec \& Fišer 2016). Similar to these findings, Best and Delmege 
(2012) in a small-scale study with 15 respondents (66\% females aged 18 to 62 ) from Western Australia found that the use of marketplace metaphors or a "shopping culture of dating" (Best \& Delmege 2012) affected the online daters by decreasing their willingness to date. Based on these findings, further research could study the relationship between objectification of others and self in online dating use and mental health problems. Overall, the studies covered in this section demonstrate that online dating is perceived as more dangerous than traditional offline dating. The perceived risks appear to coincide across studies, mainly involving deception, sexual harassment, and finding untrustworthy people. However, only one study (Choi et al. 2018) identified the risks of being abused in relation to dating apps use, although the findings in this study may be somewhat unspecific because it was not assessed whether the experienced abuse resulted from online or offline sources of aggression. There is agreement on the general perception of risks and the objectification effect by filtering through multiple profiles. Findings come mainly from qualitative studies; therefore, they are informative, but further analysis on more representative populations using quantitative approaches is needed to support these results.

Also, to date, only two studies have exclusively focused on problematic online dating. Both studies were quantitative and developed validated psychometric scales (Orosz et al. 2016, 2018). One of the studies used a mixed-methods approach (Orosz et al. 2018). The two studies solely focused on one specific dating app (i.e. Tinder). In the first study, Orosz et al. (2016) developed a psychometric instrument to assess the problematic use of Tinder (Problematic Tinder Use Scale, PTUS). This self-report measure is based on the components model of addiction (Griffiths 2005), which comprises six characteristics of addiction: salience, mood modification, tolerance, withdrawal, conflict and relapse. In order to validate the PTUS, a sample of 430 Hungarian Tinder users (243 females; mean age $=22.53$ years) was selected, and the six-item unidimensional structure showed good reliability and factor structure. In the second study, Orosz et al. (2018) carried out three different studies. First, with a sample of 414 Hungarian respondents (246 females; mean age $=22.71$ years), the TUMS (Tinder Use Motivations Scale) was developed, resulting in the identification of four main motivations of Tinder use arising from a 16-item first-order factor structure (i.e. sex, love, self-esteem enhancement, and boredom). In the second study, with a convenience sample of 346 participants (165 females; mean age $=22.02$ ), measures were taken from the newly developed TUMS, together with the PTUS, and the Hungarian Big Five Inventory (John \& Srivastava 1999). The results were weak in relation to personality factors and the four main motivations for Tinder use. However, self-esteem enhancement was related to Tinder use. In the third study, 298 participants (177 females; mean age $=25.09$ ) were assessed with the TUMS, PTUS, the Hungarian 10-item Rosenberg Self-Esteem Scale (RSES) (Randal et al. 2015; Urbán et al. 2014), and the Hungarian version of the Basic Psychological Need Satisfaction and Need Frustration Scale (BPNSFS) (Chen et al. 2015; 
Tóth-Király et al. 2018). The results showed that relatedness frustration (i.e. needs not met by affection and care from relevant others) predicted the motivation of self-esteem enhancement which was found to be one of the motivations associated with problematic use of Tinder, together with the sex motive. Overall, the studies presented in this section are not sufficient in terms of quantity to consider online dating addiction as an entity. However, the studies are of general interest to researchers considering the widespread use of dating apps and provide insight in relation to factors such as self-esteem and sex-searching that may be related to the development of problematic patterns of use. Even though there is a scarcity of literature examining problematic use of online dating, there is some research that appears to support the findings presented in this section.

\subsection{Positive Effects}

Sumter et al. (2017) conducted a study in which they distributed an online survey to Dutch adults aged $18-30(\mathrm{~N}=163)$ to learn more about what motivates adults to use Tinder. They uncovered six positive motivations: Love, casual sex, ease of communication, self-worth validation, thrill of excitement, and trendiness. What is most interesting is that the love motivation appeared to be stronger than the casual sex motivation, suggesting that although some may use Tinder for hooking up with other people, Tinder "should not be seen as merely a fun, hook-up app without any strings attached, but as a multifunctional tool that satisfies various needs among emerging adults" (Sumter et al., 2017). Other studies seem to reveal similar findings about motivations for mobile apps usage for dating including love (Bryant \& Sheldon 2017), relationship and hooking up (Bryant \& Sheldon; Lutz \& Ranzini, 2017), and traveling, self-validation and entertainment (Lutz \& Ranzini, 2017). On the other hand, there is also research that reveals a disconnect between people and Tinder. Guo (2017) stated that the problem lies in that people turn to dating applications to solve a problem found in the real world: fear of rejection. This causes a spiral of disappointment when 5 men get “... swipe-happy on Tinder, women can get overwhelmed with attention, making them choosier. This makes men even more desperate, and even less discerning about who they like. So, the situation descends into confusion" (para. 8). It is precisely for this reason that this study finds an invitation for research. If so many people are using dating applications, yet, at the same time are displeased by them, there must be something worth capitalizing on that could lead to higher quality matches, ultimately satisfying dating app usage motivations.

A potential answer to this question could be in how people practice modality switching, or the act of moving from a dating app medium to a face-to-face (FtF) conversation. As mentioned previously, Tinder is highly superficial and influences people to make multiple swipes across a large dating pool, which ultimately leads to low quality matches that never go beyond the dating application medium (Guo, 2017). In 2014, Ramirez, Sumner, Fleuriet, and Cole attempted to uncover the answer to this question by studying if the duration of time talking 
on a dating platform played a factor in FtF interaction outcomes. They found that there seems to be a tipping point in which relational outcomes are dampened when switching modalities from dating applications to FtF interactions. If people meet within three weeks of discovering each other on the dating app, there is a much higher likelihood the FtF interaction will be positive, but after six weeks, there is a higher chance it will negatively affect relational outcomes. This is potentially because people attempt to present their best selves on their profiles, and when people match they fill in the blanks between what they perceive and their expectations. This means that when partners meet earlier they "might be able to accept any minor differences between their expectations and reality, but partners who wait too long may experience increased uncertainty 6 when the person they interacted with fails to meet their well-developed expectations FtF" (Ramirez et al., 2014).

\subsection{Uses and Gratifications Theory}

The uses and gratifications theory $(\mathrm{U} \& \mathrm{G})$ has been widely used to describe how and why people use particular media to satisfy their needs (Ruggiero, 2000). Particularly, the theory explains that a person's motivations and gratifications sought from media explains media sources regularly attended to. U\&G has been applied to study the relationship between people and video games (De Simone, 2013), television (Lin, Chen, \& Sung, 2018), smartphones (Soto, Almarza, \& Wilkinson, 2017), social media (Ferris \& Hollenbaugh, 2018), and the focus of this research, online dating (Sumter et al., 2017). In fact, it's because of the uses and gratifications theory's ability to explain the relationship between internet technology and humans that the theory has been resurrected as a relevant theoretical approach. Earlier conceptions by Katz, Blumler, and Gurevitch (1973) proposed the following five basic assumptions of the theory: 1) The audience is perceived as active; 2) The audience member is responsible for linking the need gratification and media choice; 3) Media compete with other media for need satisfaction; 4) Methodologically, the data can be extrapolated directly from the individual audience members to meet the goals of $U \& G$ research; 5) Value judgements about the cultural significance of mass communication should be suspended while audience orientations are explored on their own terms (pp. 510-511) 10. Ruggiero (2000) suggests that while it is important to note that the uses and gratifications theory does bear criticisms, the "assertiveness of U\&G researchers to continuously critique basic assumptions suggests a dynamic and evolving theoretical atmosphere, especially as we depart the industrial era for the postindustrial age" (p. 26). Additionally, he notes that there are three assumptions that have evolved with the idea of an active audience which are:

1) Media selection is initiated by the individual;

2) Expectations for media use are produced from individual predispositions, social interaction, and environmental factors;

3) The behavior of an active audience is goal-directed (p. 11). 
Recently, online dating has become a growing phenomenon and researchers have been employing $U$ \& $G$ as a means of understanding it. Some of the gratification typologies that have derived from the results have been love, casual sex, ease of communication, self-worth validation, thrill of excitement, and entertainment (Sumter et al., 2017). In their study over motivations for using Tinder, they concluded that men were more likely to use Tinder for the thrill of the excitement, ease of communication, and casual sex more than women do. However, what is even more interesting is that their data supported the notion that the love motivation was stronger than the casual sex motivation, suggesting a counter-argument to the hookup/sex connotation, and that "Tinder should not be seen as merely a fun, hookup app without any strings attached, but as a new way for emerging adults to initiate committed romantic relationships" (p. 67). Research by Ranzini and Lutz (2017) found six similar motives of use for online dating; hookup/sex, friendship, relationship, traveling, self-validation, and entertainment. In this study, men were more likely motivated by sex, traveling, and relationship seeking, whereas women were more motivated by friendship and self-validation. Mirroring this study, Lutz and Ranzini (2017) used the same six motives to study audience privacy concerns and found that different motives "affect social privacy concerns more strongly than institutional concerns" (p.1). Lastly, Gatter and Hodkinson (2016) found that their data did not show any difference between online dating websites, and other online dating services that were uniquely application-based only. However, even if the motivations are the same for both platforms, Manley (2017) states that ...if you are to meet traditional love through Tinder, there becomes a stigma on that relationship. The application overall is superficially based, thus, it is hard for consumers to find true depth to it, unless they actually do. Also, most respondents stated that they can meet a potential partner on Tinder; however, they would still prefer to meet their partners offline (p. 52).

\section{Future Directives on how to Maintain a Healthy Offline Intimate Relationship while Using Online Applications, during a Pandemic}

Here, we would be listing out some of the future directions on how one can help keep and maintain offline (face to face) intimate affairs by ways of avoiding and also withstanding the temptations that come with online dating applications, especially during a pandemic.

1) Avoid a conversation that begins with "hook-ups". In a previous text, it was earlier explained that hookups especially while using the tinder app meant "can we have sex" and such conversations should not be tolerated to help avoid the desire to cheat on an offline partner.

2) Be able to regulate time spent in the application and time spent with your offline lover, that is allocating a larger portion of time and attention to him or her. Even during a pandemic and social distancing is advised; try to call and text 
often with your unconnected partner to ensure an easy flow of communication to maintain a healthy relationship.

3) Even when one has downloaded the tinder dating to meet a new friend or lover to kill boredom due to havoc, he or she should always keep in mind that your online partner is anonymous and could be all pretending to have fallen in love with you thereby showering you with all the attention or maybe worst, they could be serial killers. Notwithstanding, when you get to understand their anonymity, then you can place more value and focus on your offline partner to keep your relationship healthy.

4) Be content. Do not be carried away by the wealthy lifestyles, body physique, and attention that an online lover or friend is showing off on the app, it could be fake as he may have his pictures filtered or might even be impersonating another. This would not only distract the individual, but it could also bring out discontentment, as he or she may begin comparing their offline lover to an unreal online one.

5) An individual can download whichever social media applications they desire to have his or her fun and kill the boredom, however, they should always ensure that they avoid getting too intimate, that is; avoid getting sexually attracted to their online lover. This might destroy the honesty, respect, and commitment rules that are encompassed in essential characteristics of a healthy relationship. In essence, it might pose a huge threat or at worst, put an end to the unconnected (offline) relationship as well.

\section{Conclusion}

The overriding purpose of this study is to establish both the negative and positive effects that online dating software, (using tinder as a case study) has on healthy offline (face to face) intimate relationships during the corona virus outbreak. Based on the outcome of the study, it can be concluded that during the COVID-19 pandemic which brought about loneliness and boredom (due to social distancing and lockdowns of major parts of most countries to help contain the spread of the virus), there was a high increase of tinder users which in both positive (such as realizing and detecting when one is being real and fake, etc.) and negative ways (low communication, little or no attention, etc.), might have led to both havoc and realizations. However, the work further reveals that there are more negative effects than the positive ones and at such gave future directives on how to avoid and also withstand the temptations that come with using an online dating application, especially during a pandemic to help maintain a healthful personal affair with one's unconnected partner.

\section{Acknowledgements}

First and foremost, my gratitude goes to the Almighty God for his infinite mercy throughout the completion of this research work. A Special thanks to Associate Professor Levi, Obijiofor for his constant support towards this work. Sincere 
Gratitude's to the editors of this journal who has found this research paper worthy of publication. Also, I would like to thank my family, Pastor Mrs Joy NgoziOkoye, $\mathrm{Mr}$ and Mrs Christian mbonu, Dr and DrIzuchukwuMetu, DrAllwellOkoye and Mr Divine Okoye for both their financial support and ideas to this work. Finally, I am grateful to my amaaing friends, Mr Onyedikachi Obimma and $\mathrm{Mr}$ Odetunde Damilare Emmanuel for for their intellectual support during this Project.

\section{Conflicts of Interest}

The author declares no conflicts of interest regarding the publication of this paper.

\section{References}

Ahuvia, A. C., \& Adelman, M. B. (1992). Formal Intermediaries in the Marriage Market: A Typology and Review. Journal of Marriage and the Family, 54, 452-463. https://doi.org/10.2307/353076

Allen, J. (2008). Attachment in Adolescence. In J. Cassidy, \& P. Shaver (Eds.), Handbook of Attachment: Theory, Research and Clinical Implications (2nd ed., pp. 419-435). New York: Guilford Press.

Amato, P. R., \& DeBoer, D. D. (2001). The Transmission of Marital Instability across Generations: Relationship Skills or Commitment to Marriage? Journal of Marriage and the Family, 63, 1038-1051. https://doi.org/10.1111/j.1741-3737.2001.01038.x

Arnould, E. J., \& Thompson, C. J. (2005). Consumer Culture Theory (CCT): Twenty Years of Research. Journal of Consumer Research, 31, 868-882. https://doi.org/10.1086/426626

Baumeister, R. F., \& Leary, M. R. (1995). The Need to Belong: Desire for Interpersonal Attachments as a Fundamental Human Motivation. Psychological Bulletin, 117, 497-529. https://doi.org/10.1037/0033-2909.117.3.497

Baxter, H., \& Cashmore, P. (2013). Tinder: The Shallowest Dating app Ever? http://www.theguardian.com/lifeandstyle/2013/nov/23/tinder-shallowest-datingapp-ever

Best, K., \& Delmege, S. (2012). The Filtered Encounter: Online Dating and the Problem of Filtering through Excessive Information. Social Semiotics, 22, 237-258. https://doi.org/10.1080/10350330.2011.648405

Bryant, K., \& Sheldon, P. (2017). Cyber Dating in the Age of Mobile Apps: Understanding Motives, Attitudes, and Characteristics of Users. American Communication Journal, $19,1-15$

Cacioppo, J. T., Hawkley, L. C., Crawford, L. E., Ernst, J. M., Burleson, M. H., Kowalewski, R. B., \& Berntson, G. G. (2002). Loneliness and Health: Potential Mechanisms. Psychosomatic Medicine, 64, 407-417. https://doi.org/10.1097/00006842-200205000-00005

Cali, B. E., Coleman, J. M., \& Campbell, C. (2013). Stranger Danger? Women's Self-Protection Intent and the Continuing Stigma of Online Dating. Cyberpsychology, Behavior and Social Networking, 16, 853-857. https://doi.org/10.1089/cyber.2012.0512

Chen, B., Vansteenkiste, M., Beyers, W., Boone, L., Deci, E. L., Van der Kaap-Deeder, J., Ryan, R. M. et al. (2015). Basic Psychological Need Satisfaction, Need Frustration, and Need Strength across Four Cultures. Motivation and Emotion, 39, 216-236. https://doi.org/10.1007/s11031-014-9450-1

Choi, E. P. H., Wong, J. Y. H., \& Fong, D. Y. T. (2018). An Emerging Risk Factor of Sexual Abuse: The Use of Smartphone Dating Applications. Sexual Abuse: Journal of Re- 
search and Treatment, 30, 343-366. https://doi.org/10.1177/1079063216672168

Cohen, S., Frank, E., Doyle, W. J., Skoner, D. P., Rabin, B. S., \& Gwaltney, J. M. (1998). Types of Stressors That Increase Susceptibility to the Common Cold in Healthy Adults. Health Psychology, 17, 214-223. https://doi.org/10.1037/0278-6133.17.3.214

Colao, J. (2013). Not Just for Hookups: Tinder Looks to Conquer Business Networking. http://www.forbes.com/sites/jicolao/2013/04/08/tinder-for-business-dating-applooks-t o-conquer-other-matchmaking-verticals/

Coontz, S. (2005). Marriage, a History. New York: Viking.

Couch, D., \& Liamputtong, P. (2007). Online Dating and Mating: Perceptions of Risk and Health among Online Users. Health, Risk and Society, 9, 275-294. https://doi.org/10.1080/13698570701488936

Couch, D., Liamputtong, P., \& Pitts, M. (2012). What Are the Real and Perceived Risks and Dangers of Online Dating? Perspectives from Online Daters: Health Risks in the Media. Health, Risk and Society, 14, 697-714.

https://doi.org/10.1080/13698575.2012.720964

Diener, E., \& Seligman, M. E. P. (2002). Very Happy People. Psychological Science, 13, 81-84. https://doi.org/10.1111/1467-9280.00415

eHarmony.com. (2011). How We Match.

Erjavec, K., \& Fišer, S. Ž. (2016). Aging Adults about Online Dating: "I Am Back on the Relationship Market”. Polish Sociological Review, 195, 361-371.

Ferris, A. L., \& Hollenbaugh, E. E. (2018). A Uses and Gratifications Approach to Exploring Antecedents to Facebook Dependency. Journal of Broadcasting \& Electronic Media, 62, 51-70. https://doi.org/10.1080/08838151.2017.1375501

Forthofer, M. S., Markman, H. J., Cox, M., Stanley, S., \& Kessler, R. C. (1996). Associations between Marital Distress and Work Loss in a National Sample. Journal of Marriage and the Family, 58, 597-605. https://doi.org/10.2307/353720

Frost, J. H., Chance, Z., Norton, M. I., \& Ariely, D. (2008). People Are Experience Goods: Improving Online Dating with Virtual Dates. Journal of Interactive Marketing, 22, 51-61. https://doi.org/10.1002/dir.20107

Galbin, A. (2014). An Introduction to Social Constructionism. Social Research Reports, 26, 82-92.

Gallo, L. C., Troxel, W. M., Matthews, K. A., \& Kuller, L. H. (2003). Marital Status and Quality in Middle-Aged Women: Associations with Levels and Trajectories of Cardiovascular Risk Factors. Health Psychology, 22, 453-463.

https://doi.org/10.1037/0278-6133.22.5.453

Gatter, K., \& Hodkinson, K. (2016). On the Differences between Tinder versus Online Dating Agencies: Questioning a Myth. An Exploratory Study. Cogent Psychology, 3, 1-12. https://doi.org/10.1080/23311908.2016.1162414

Greenberg, B. S. (1974). Gratifications of Television Viewing and Their Correlates for British Children. In J. G. Blumler, \& E. Katz (Eds.), The Uses of Mass Communications: Current Perspectives on Gratifications Research (pp. 71-92). Beverly Hills, CA: Sage.

Griffiths, M. (2005). A “Components" Model of Addiction within a Biopsychosocial Framework. Journal of Substance Use, 10, 191-197.

https://doi.org/10.1080/14659890500114359

Guo, J. (2017). Why Is Everyone Miserable on Tinder. Washington Post. https://www.washingtonpost.com/news/wonk/wp/2016/07/26/why-everyone-ismiserab le-on-tinder/?utm term=.cbbe90fofald 
Heino, R. D., Ellison, N. B., \& Gibbs, J. L. (2010). Relation Shopping: Investigating the Market Metaphor in Online Dating. Journal of Social and Personal Relationships, 27, 427-447. https://doi.org/10.1177/0265407510361614

Holt-Lunstad, J., Smith, T. B., \& Layton, J. B. (2010). Social Relationships and Mortality Risk: A Meta-Analytic Review. PLoS Medicine, 7, e1000316. https://doi.org/10.1371/journal.pmed.1000316

John, O. P. P., \& Srivastava, S. (1999). The Big Five Trait Taxonomy: History, Measurement, and Theoretical Perspectives. In L. Pervin, \& O. John (Eds.), Handbook of Personality: Theory and Research (2nd ed., pp. 102-138). New York: Guilford.

Katz, E., Blumler, J., \& Gurevitch, M. (1973). Uses and Gratifications Research. The Public Opinion Quarterly, 37, 509-523. http://www.jstor.org/stable/2747854 https://doi.org/10.1086/268109

Katz, E., Blumler, J., \& Gurevitch, M. (1974). Utilization of Mass Communication by the Individual. In J. Blumler, \& E. Katz (Eds.), The Uses of Mass Communication: Current Perspectives on Gratifications Research. Beverly Hills, CA: Sage.

Katz, E., Haas, H., \& Gurevitch, M. (1973). On the Use of the Mass Media for Important Things. American Sociological Review, 38, 164-181. https://doi.org/10.2307/2094393

Kerckhoff, A. C. (1964). Patterns of Homogamy and the Field of Eligibles. Social Forces, 42, 289-297. https://doi.org/10.2307/2575531

Kiecolt-Glaser, J. K., Loving, T. J., Stowell, J. R., Malarkey, W. B., Lemeshow, S., Dickinson, S. L., \& Glaser, R. (2005). Hostile Marital Interactions, Proinflammatory Cytokine Production, and Wound Healing. Archives of General Psychiatry, 62, 1377-1384.

https://doi.org/10.1001/archpsyc.62.12.1377

Lin, J., Chen, K., \& Sung, Y. (2018). Understanding the Nature, Uses, and Gratifications of Social Television: Implications for Developing Viewer Engagement and Network Loyalty. Journal of Broadcasting \& Electronic Media, 62, 1-20. https://doi.org/10.1080/08838151.2017.1402904

Lutz, C., \& Ranzini, G. (2017). Where Dating Meets Data: Investigating Social and Institutional Privacy Concerns on Tinder. Social Media \& Society, 3, 1-12. https://doi.org/10.1177/2056305117697735

Manley, T. (2017). Millennials' Use of Online Applications for Romantic Development. In N. M. Punyanunt-Carter, \& J. S. Wrench (Eds.), The Impact of Social Media in Modern Romantic Relationships (pp. 1-12). London: Lexington Books.

Mitchell, R. L. (2009). Online Dating: Analyzing the Algorithms of Attraction. PCWorld. http://www.pcworld.com/article/159884-2/online dating analyzing the algorithms of attraction.html

Moore, C. D., \& Waterman, C. K. (1999). Predicting Self-Protection against Sexual Assault in Dating Relationships among Heterosexual Men and Women, Gay Men, Lesbians, and Bisexuals. Journal of College Student Development, 40, 132-140.

Nielsenwire.com (2009). Online Dating and Advertising Prove to Be a Good Match. http://blog.nielsen.com/nielsenwire/consumer/online-dating-and-advertisingprove-tobe-a-good-match

OkCupid.com (2011)

https://mashable.com/roundup/best-free-dating-sites-apps-hinge-tinder-okcupid/

Orosz, G., Benyó, M., Berkes, B., Nikoletti, E., Gál, É., Tóth-Király, I., \& Bőthe, B. (2018). The Personality, Motivational, and Need-Based Background of Problematic Tinder Use. Journal of Behavioral Addictions, 7, 301-316.

https://doi.org/10.1556/2006.7.2018.21 
Orosz, G., Tóth-Király, I., Bőthe, B., \& Melher, D. (2016). Too Many Swipes for Today: The Development of the Problematic Tinder Use Scale (PTUS). Journal of Behavioral Addictions, 5, 518-523. https://doi.org/10.1556/2006.5.2016.016

Ramirez, A., Sumner, E. M. B., Fleuriet, C., \& Cole, M. (2014). When Online Dating Partners Meet Offline: The Effect of Modality Switching on Relational Communication between 34 Online Daters. Journal of Computer-Mediated Communication, 20, 99-114. https://doi.org/10.1111/jcc4.12101

Randal, C., Pratt, D., \& Bucci, S. (2015). Mindfulness and Self-Esteem: A Systematic Review. Mindfulness, 6, 1366-1378. https://doi.org/10.1007/s12671-015-0407-6

Rightler-McDaniels, J., \& Hendrickson, E. (2014). Hoes and Hashtags: Constructions of Gender and Race in Trending Topics. Social Semiotics, 24, 175-190.

https://doi.org/10.1080/10350330.2013.859355

Rosenfeld, M. J. (2010). Meeting Online: The Rise of the Internet as a Social Intermediary. The Population Association of America Meetings, Dallas.

Rosenfeld, M. J., \& Thomas, R. J. (2010). Meeting Online: The Rise of the Internet as a Social Intermediary. Unpublished Manuscript, Stanford, CA: Department of Sociology, Stanford University.

Rubin, A. M. (2009). The Uses-and-Gratifications Perspective on Media Effects. In J. Bryant, \& M. B. Oliver (Eds.), Media Effects: Advances in Theory and Research (3rd ed.). New York, NY: Routledge.

Ruggiero, T. E. (2000). Uses and Gratifications Theory in the 21st Century. Mass Communication \& Society, 3, 3-37. https://doi.org/10.1207/S15327825MCS0301 02

Sánchez, V., Muñoz-Fernández, N., \& Ortega-Ruíz, R. (2015). “Cyberdating Q-A”: An Instrument to Assess the Quality of Adolescent Dating Relationships in Social Networks. Computers in Human Behavior, 48, 78-86.

https://doi.org/10.1016/j.chb.2015.01.006

Sbarra, D. A., Law, R. W., \& Portley, R. M. (2011). Divorce and Death: A Meta-Analysis and Research Agenda for Clinical, Social, and Health Psychology. Perspectives on Psychological Science, 6, 454-474. https://doi.org/10.1177/1745691611414724

Schau, H. J., \& Gilly, M. C. (2003). We Are What We Post? Self-Presentation in Personal Web Space. Journal of Consumer Research, 30, 385-404. https://doi.org/10.1086/378616

Seigel, D. (1999). Attachment. In D. Seigel (Ed.), The Developing Mind: How Relationships and the Brain Interact to Shape Who We Are (pp. 67-120). New York: Guilford Press.

Smith, A., \& Duggan, M. (2013). Online Dating and Relationships. http://www.pewinternet.org/2013/10/21/online-dating-relationships/

Solis, R. J. C., \& Wong, K. Y. J. (2019). To Meet or Not to Meet? Measuring Motivations and Risks as Predictors of Outcomes in the Use of Mobile Dating Applications in China. Chinese Journal of Communication, 12, 206-225. https://doi.org/10.1080/17544750.2018.1498006

Soto, L. R., Almarza, B. C., \& Wilkinson, K. T. (2017). Young Hispanic's Motivations to Use Smartphones: A Three-Country Comparative Study. Communication \& Society, 30, 13-25.

Straus, M. A., Hamby, S. L., Boney-McCoy, S., \& Sugarman, D. B. (1996). The Revised Conflict Tactics Scale (CTS2): Development and Preliminary Psychometric Data. Journal of Family Issues, 17, 283-316. https://doi.org/10.1177/019251396017003001

Subscription Site Insider (2011). Dating and Matchmaking Site Benchmark Report. New- 
port, RI: Anne Holland Ventures.

Sumter, S. R., Vandenbosch, L., \& Ligtenberg, L. (2017). Love Me Tinder: Untangling Emerging Adults' Motivations for Using the Dating Application Tinder. Telematics and Informatics, 34, 67-78. https://doi.org/10.1016/j.tele.2016.04.009

Tóth-Király, I., Morin, A. J. S., Bőthe, B., Orosz, G., \& Rigó, A. (2018). Investigating the Multidimensionality of Need Fulfillment: A Bifactor Exploratory Structural Equation Modeling Representation. Structural Equation Modeling, 25, 267-286. https://doi.org/10.1080/10705511.2017.1374867

Urbán, R., Szigeti, R., Kökönyei, G., \& Demetrovics, Z. (2014). Global Self-Esteem and Method Effects: Competing Factor Structures, Longitudinal Invariance, and Response Styles in Adolescents. Behavior Research Methods, 46, 488-498. https://doi.org/10.3758/s13428-013-0391-5

Vandeweerd, C., Myers, J., Coulter, M., Yalcin, A., \& Corvin, J. (2016). Positives and Negatives of Online Dating According to Women 50+. Journal of Women and Aging, 28, 259-270. https://doi.org/10.1080/08952841.2015.1137435

Veroff, J., Kulka, R. A., \& Douvan, E. (1981). Mental Health in America: Patterns of HelpSeeking from 1957 to 1976. New York, NY: Basic Books.

Whitty, M. T., \& Carr, A. (2006). Cyberspace Romance: The Psychology of Online Relationships. New York: Palgrave Macmillan. https://doi.org/10.1007/978-0-230-20856-8 